\section{The eye lens cytoskeleton}

\begin{abstract}
During lens cell differentiation there are a number of very characteristic morphological changes that occur. These include a 50- to 100fold increase in cell length as the equatorial lens epithelial cells differentiate into fibre cells and the loss of the cellular organelles such as mitochondria, nuclei, Golgi apparatus and endoplasmic reticulum. Coincident with these changes are dramatic alterations in the organisation of the lens fibre cell cytoskeleton and in particular the lens-specific intermediate filament network comprising CP49 and filensin. Cell shape and cell polarisation as well as tissue integrity are all processes that depend upon the cytoskeleton and are therefore important to the lens. The unique aspects of the lenticular cytoskeleton are the subject of this review.
\end{abstract}

Key words CP49, Cytoskeleton, Differentiation, Filensin, Intermediate filaments, Lens

\section{The lenticular cytoskeleton}

In common with other cells, lens cells possess microfilaments, microtubules and intermediate filaments (Fig. 1). It is expected that they also perform equivalent functions in the lens as found in other cell types. Thus, the actin cytoskeleton, through the actions of actinbinding proteins and motor proteins, will facilitate changes in cell shape, strengthen cell-cell contacts and cell-extracellular matrix interactions, and define plasma membrane compartments. Likewise the microtubule cytoskeleton will direct intracellular transport processes as well as contributing to the distribution of organelles. Intermediate filaments are major structural elements of cells helping them to resist physical stresses, which in the context of the primate lens will include lens accommodation. Of all these cytoskeletal systems it is the intermediate filaments of the eye lens that are the most distinct and for which a direct link with cataract has recently been suggested.
R.A. QUINLAN, A. SANDILANDS,

J.E. PROCTER, A.R. PRESCOTT,

A.M. HUTCHESON, R. DAHM,

C. GRIBBON, P. WALLACE, J.M. CARTER
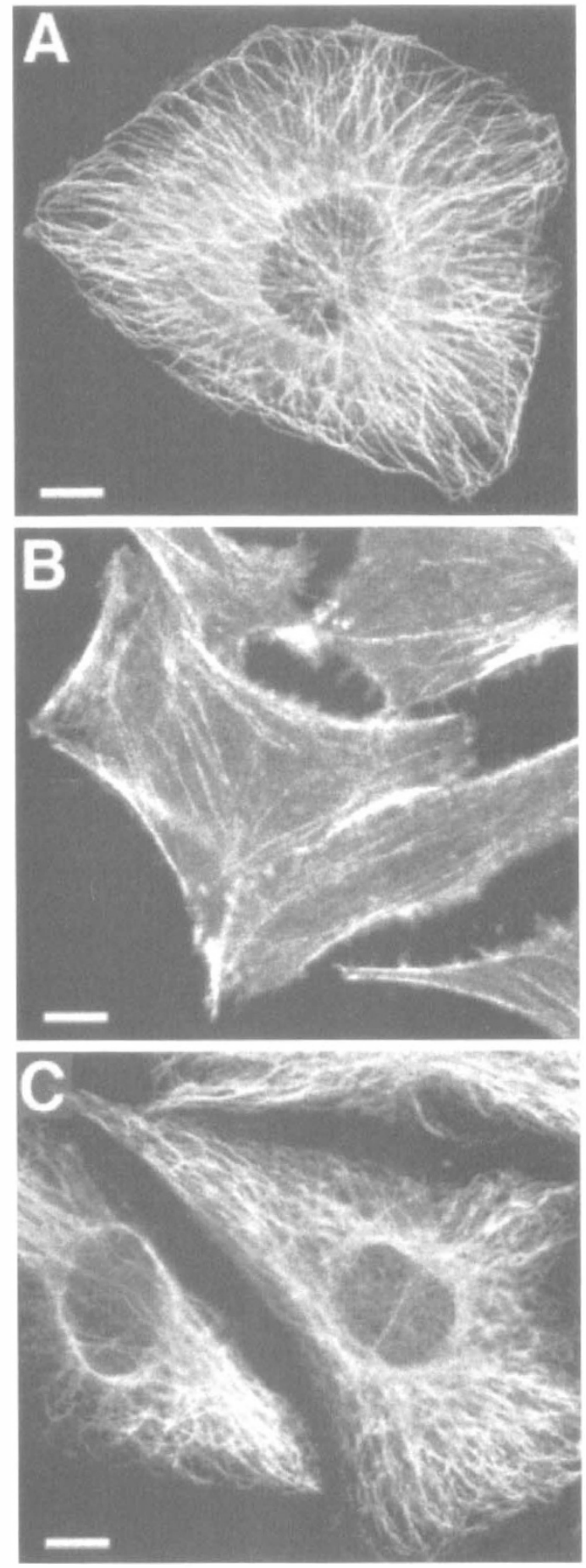

R.A. Quinlan

A. Sandilands

J.E. Procter

A.R. Prescott

A.M. Hutcheson

R. Dahm

C. Gribbon

P. Wallace

J.M. Carter

Department of Biochemistry

Medical Sciences Institute

The University

Dundee, Scotland, UK

Dr R.A.Quinlan $\square$

Department of Biochemistry

The University

Dundee DD1 5EH

Scotland, UK

Tel: +44 (0)1382344752

Fax: +44 (0)1382 201603

e-mail:

raquinlan@bad.dundee.ac.uk

R.A.Q. and J.M.C.

acknowledge the financial support of the Wellcome Trust. J.E.P. and R.D. are supported by MRC and BBSRC-CASE studentships respectively. The support of Pharmacia-Upjohn as the industrial sponsor of the BBSRC-CASE studentship is acknowledged. C.G. is supported by a Fight for with an antibody to $\alpha$-tubulin $(A)$, phalloidin to actin (B) and an antibody to vimentin (C). Scale bars represent $10 \mu \mathrm{m}$. 
Table 1. The intermediate filament protein family

\begin{tabular}{llll}
\hline Intermediate filament type & Protein name & Molecular weight $\left(\times 10^{-3}\right)$ & Cell/tissue location \\
\hline I & Keratin 9-20 & $40-64$ & Epithelial cells \\
II & Keratin 1-8 & $52-68$ & Epithelial cells \\
III & Vimentin & 55 & Mesenchymal cells \\
& Desmin & 53 & Muscle cells \\
& GFAP & 51 & Glia and astrocytes \\
& Peripherin & 54 & Neuronal cells \\
IV & Neurofilament proteins: & & Neurons \\
& NF-L/NF-M $/$ NF-H & Neurons \\
& $\alpha$-internexin & $70-160$ & Neuroepithelial stem cells and muscle \\
& Nestin & 56 & \\
V & 240 & Differentiated cells \\
& Nuclear lamins: & & All cells \\
\hline
\end{tabular}

${ }^{a}$ The apparent mobility of these proteins by SDS-PAGE is quite different from the calculated molecular weights determined from the amino acid sequence.

\section{Intermediate filaments of the eye lens}

Our own studies have concentrated on the intermediate filament proteins found in the lens, which have led to a number of important discoveries. Firstly, through the cloning and sequencing of the two lens-specific proteins, $\mathrm{CP} 49^{1-6}$ and filensin, ${ }^{7-12}$ the homology of these proteins to the intermediate filament protein family was established. Secondly, CP49 and filensin were found in a complex with two other major lens proteins, $\alpha \mathrm{A}-$ and $\alpha \mathrm{B}-$ crystallin, ${ }^{13,14}$ which are protein chaperones and which are essential for lens transparency. This complex of chaperones and intermediate filaments forms a specific structure with a very distinctive morphology called the beaded filament. It is found only in the lens. ${ }^{15}$ Thirdly, the mechanism of assembly for CP49 proteins and filensin is apparently different from that observed for other intermediate filament proteins, which has challenged several of the central dogmas concerning intermediate filament assembly. ${ }^{14,16,17}$ Lastly, the discovery that mutations in $\alpha \mathrm{B}$-crystallin can induce the collapse of intermediate filament networks ${ }^{18}$ shows intermediate and beaded filaments to be important physiological targets for the chaperone function of $\alpha \mathrm{B}$ crystallin $^{19}$ and suggests the beaded filament is a key structural element required for lens transparency.

\section{Diseases caused by intermediate filaments and their associated proteins}

Intermediate filaments are some of the most resilient structures present in the cell. ${ }^{20} \mathrm{~A}$ number of inherited diseases have been discovered which are due to mutations in intermediate filament proteins or their associated proteins. ${ }^{21}$ These include skin blistering diseases (reviewed $\mathrm{in}^{21}$ ), muscular dystrophy, ${ }^{22}$ myopathies, ${ }^{23,24}$ corneal dystrophies ${ }^{25}$ and also lens cataract. ${ }^{18,26}$ A defective intermediate filament network severely compromises the structural integrity of the cell as well as the tissue comprising these cells. ${ }^{27}$ For instance, the first diseases attributed to mutations in intermediate filament proteins were the skin blistering diseases. Here, mutations in the keratins, the intermediate filament proteins found in epithelial cells, caused collapse of the filament network in the epidermal cells. The barrier function of the epidermis is lost which, depending on the mutation, can present a range of phenotypes from skin blistering, in response to mild stress, to the shedding of large areas of epidermis in the most severe cases. More recently, mutations in the muscle-specific intermediate filament protein, desmin, have been found to cause desmin related myopathy $\left(\mathrm{DRM}^{23,24}\right)$. This disease can also be caused by a mutation in $\alpha \mathrm{B}$-crystallin, ${ }^{18}$ demonstrating the importance of
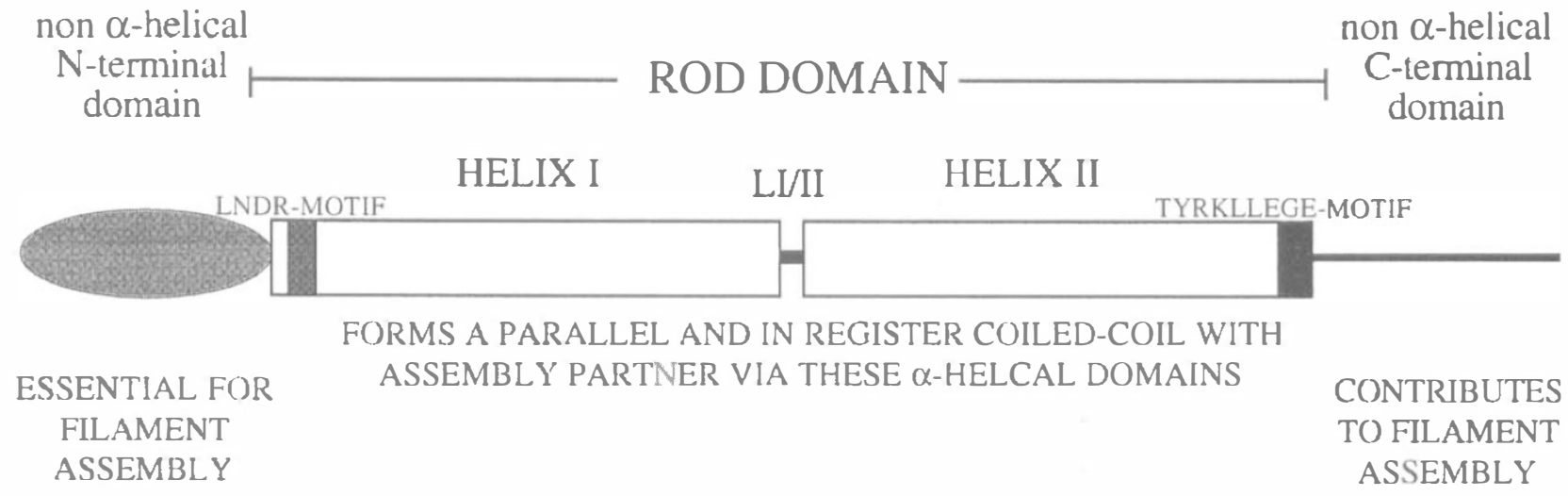

Fig. 2. Schematic representation of the structural features common to the intermediate protein family. 
associated proteins to intermediate filament function. Patients with DRM caused by $\alpha \mathrm{B}$-crystallin mutations also present with cataract, suggesting an important role for intermediate filaments in lens transparency. In mouse models of cataractogenesis, disruption of the normal expression pattern and levels of intermediate filament proteins occurs in the lenses of these mice. ${ }^{28-31}$

\section{Intermediate filament family}

There are over 60 different gene products attributed to the intermediate filament protein family on the basis of their primary amino acid sequence similarities, assembly characteristics and gene structure (Table 1). These proteins are arranged into five major classes. The type I and II proteins comprise the keratins, which cover those intermediate filament proteins found in epithelia. The type III proteins are GFAP, desmin, peripherin and vimentin, which are specific for astrocytes, muscle, peripheral nerves and cells of mesenchymal origin, respectively. The type IV proteins are the neurofilament proteins, including $\alpha$-internexin, which are all found largely in neurons. Lastly type $\mathrm{V}$ are the nuclear lamins, which are found in all cells that possess a nucleus. More recently, the discovery of additional vertebrate intermediate filament proteins such as CP49 (see below), filensin (see below), synemin ${ }^{32}$ and paranemin, ${ }^{33}$ which do not fit easily into either one of the established protein types, may mean that this categorisation will change.

All intermediate filament proteins share a number of common primary and secondary structural

characteristics (Fig. 2). There is a central rod domain, comprising mainly $\alpha$-helix, which is flanked by non- $\alpha$ helical domains. The $\mathrm{N}$-terminal non- $\alpha$-helical domain is very important in the assembly of intermediate filaments, whereas the C-terminal non- $\alpha$-helical domain will contribute to assembly but is more involved in specific functions attributable to that particular intermediate filament protein. The central rod domain forms a coiled coil with a partner $\alpha$-helix in a parallel, in register fashion. Like other $\alpha$-helical proteins, the primary sequence can be arranged into a heptad repeat where the first and fourth residues of the repeat are usually hydrophobic to form a seam promoting the formation of the coiled coil. Dimer formation initiates the assembly process. ${ }^{34}$ It is thought that the next stage is the four chain unit, which is the soluble form of the intermediate filament proteins found in cells. ${ }^{35}$ There are conserved sequences located at either end of the central rod domain which are essential for assembly (Fig. 2). These are the LNDR- and TYRKLLEGE-motifs found at the N- and Cterminal ends of the central rod domain. ${ }^{36,37}$

Intermediate filaments themselves are apolar polymers, unlike actin filaments and microtubules which are polar. Soluble intermediate filament subunits can therefore exchange directly with the filament along its length. Tubulin and actin are restricted to exchange events at the ends of microtubules and microfilaments, respectively. ${ }^{38,39}$

\section{Intermediate filament proteins present in the lens}

In the adult vertebrate lens there are at least three different intermediate filament proteins. These include vimentin, CP49 and filensin. ${ }^{37}$ The lens has often been used as a source for the purification of vimentin, as it was considered for a long time to be the only intermediate filament protein present in the mature lens. ${ }^{40}$ Early in development, though, keratins are expressed in the primary lens fibre cells, although these are then lost. ${ }^{41}$ Vimentin itself is found in the epithelial cells and the secondary fibre cells but here the expression is restricted to the younger fibre cells. ${ }^{42,43}$ There is a distinct transition during lens fibre cell differentiation when vimentin is apparently lost from the secondary fibre cells. This point is far deeper in the lens beyond the stage where the cell organelles are lost. ${ }^{43,44}$ The lens-specific proteins, CP49 and filensin, are found at all stages of lens fibre cell differentiation including the primary lens fibre cells still found in the mature lens nucleus. ${ }^{43}$ They are, however, processed during the differentiation process. ${ }^{45}$ This information is summarised in Table 2.

In addition to these intermediate filament proteins there are several other intermediate filament proteins that deserve mention in the context of the lens. The first is a recently discovered intermediate filament protein called synemin. ${ }^{32,46}$ This protein was found first in muscle ${ }^{47}$ and was assumed to be an intermediate filament associated protein rather than a bone fide member of the intermediate filament protein family. Cloning and sequencing have now confirmed this to be an intermediate filament protein. ${ }^{32,46}$ So far the only data available are for chicken, but synemin is found early in lens development and persists in all lens fibre cells, there also being a transition point when the signal for synemin seems to disappear. ${ }^{48}$ It is believed to contribute to the formation of type III intermediate filaments as it can coassemble with desmin and vimentin ${ }^{47}$ and so one would expect the vimentin and synemin transitions to be

Table 2. Summary of the expression pattern of intermediate filament proteins in the human lens

\begin{tabular}{|c|c|c|c|c|}
\hline \multirow[b]{2}{*}{ Intermediate filament protein } & \multirow[b]{2}{*}{ Embryonic lens } & \multicolumn{3}{|c|}{ Adult lens } \\
\hline & & Primary lens fibres & Secondary lens fibres & Epithelial cells \\
\hline Keratin & + & - & - & - \\
\hline Vimentin & + & - & + & + \\
\hline $\mathrm{CP} 49^{\mathrm{a}}$ & + & + & + & - \\
\hline Filensin $^{a}$ & + & + & + & - \\
\hline
\end{tabular}

${ }^{a}$ Unpublished data. 
simultaneous. Further analyses are required to discover the relevance to the mammalian lens and in particular the human. It also needs to be considered when analysing the intermediate filament knock-outs, as in the case of the vimentin knock-out where no lens phenotype was observed. ${ }^{49}$

The other intermediate filament protein sometimes found in lens epithelium of the mouse is GFAP. So far this has only been found in certain genetic backgrounds. ${ }^{50,51}$ Its function here is unknown and indeed these claims have yet to be confirmed by independent methods. ${ }^{50}$ It is mentioned at this point for completeness as well as to illustrate the complexity of the potential expression of intermediate filament proteins in the mouse lens.

There is therefore the possibility of at least three distinct intermediate filament networks being present in lens cells. This is because vimentin and keratins do not co-polymerise with each other and will form independent networks. ${ }^{36} \mathrm{CP} 49$ and filensin do copolymerise $^{37}$ but are not expected to form filaments with either vimentin ${ }^{14}$ or keratin. ${ }^{6}$ Synemin will co-polymerise with vimentin but its ability to co-assemble with CP49 and filensin has yet to be determined. This means that the intermediate filament population is quite heterogeneous in lens fibre cells, which can not necessarily be ascribed the same function(s).

\section{Unique structural details of lens-specific intermediate filament proteins}

There are several sequence characteristics discovered for the two lens-specific intermediate filament proteins that distinguish these proteins from other proteins in the intermediate filament protein family. Firstly, CP49 contains an arginine to cysteine substitution in the assembly-critical LNDR-motif at the N-terminal end of the central $\alpha$-helical domain. If found in other intermediate filament proteins this would severely compromise the filament network, e.g. in human skin keratins, causing skin blistering diseases. ${ }^{52}$ Secondly, a CP49 splice variant, CP49ins, containing an extra 49 residues in helix $1 \mathrm{~B}$, has been found in the chicken. ${ }^{3,4}$ This feature is characteristic of the ancestral proteins from which all cytoplasmic intermediate filament proteins are derived. Lastly, CP49 is unusual among the intermediate filament protein family in that it is missing a C-terminal non- $\alpha$-helical tail domain. These features mean that CP49 does not easily fit into the currently accepted views of intermediate filament assembly, ${ }^{37}$ but understanding their contribution to the assembly of CP49/filensin is very important for understanding their function in the lens.

As with other intermediate filament proteins, many of the other sequence characteristics important to intermediate filament assembly are found in filensin and CP49. For instance, both proteins have a central $\alpha$-helical rod domain which, for filensin, has clearly been shown to be crucial for its assembly and association with $\mathrm{CP} 49^{17}$ as for other intermediate filament proteins. ${ }^{36}$ A large portion of the C-terminal domain of filensin can be deleted without preventing co-assembly with $\mathrm{CP} 49,{ }^{9}$ as has been found for other intermediate filament proteins with large non- $\alpha$-helical C-terminal domains. Some sequence characteristics of $\mathrm{CP} 49^{5}$ and filensin ${ }^{10,11}$ differ from the consensus sequence described for the intermediate filament protein family, ${ }^{37}$ and it is these which are thought to contribute to the distinctive assembly requirements and filamentous structures formed by CP49 and filensin proteins. ${ }^{14,16,37}$ For instance, the rod domain of filensin is missing four heptads in helix 2 compared with CP49. In addition to the altered consensus LNDR-motif found in CP49, filensin also has some changes in the TYRKLLEGE-motif ${ }^{37}$ that also flanks the central $\alpha$-helical rod domain (Fig. 2). The predicted length differences in the rod domains of CP49 and filensin raise important questions regarding the mechanism of CP49-filensin co-assembly, ${ }^{16,37}$ because matching lengths of the central $\alpha$-helical domain are thought to be an important prerequisite for co-assembly. ${ }^{53}$ Nevertheless, a recent proposal ${ }^{16}$ has suggested an elegant model for the incorporation of CP49 (phakinin) and filensin into a mixed polymer ${ }^{16}$ that can be tested by future experimentation.

In vitro assembly studies with $\mathrm{CP} 49$ and filensin ${ }^{14,16}$ have shown that, like the keratin class of intermediate filaments, CP49 and filensin require each other to assemble in vitro into intermediate filaments. ${ }^{6,14}$ There is still some discussion concerning the preferred ratio of CP49 to filensin for assembly, which is between $3: 1^{6}$ and 2:1. ${ }^{14}$ The formation of $10 \mathrm{~nm}$ intermediate filaments in vitro has then to be reconciled with the observation that, in the lens, CP49 and filensin are components of a lens-specific cytoskeletal filament called the 'beaded filament'. Previous biochemical and immunological investigations ${ }^{15,54-56}$ had confirmed the presence of CP49 and filensin in these filaments but were unable to apportion unequivocally either one of the proteins to the bead or backbone component of the beaded filament. Given the unique morphology of the beaded filament and that two lens-specific proteins are intimately involved in the filament, the structure and function of this lens-specific cytoskeletal element is a very important issue that needs to be resolved. In vitro assembly studies have shown that intermediate filaments with similar morphology to the beaded filaments can be generated by mixing $\alpha$-crystallins in with the CP49/filensin assembly mixture. ${ }^{14,37}$

\section{Proteolysis of filensin/CP49 and vimentin filament networks during lens cell differentiation}

Proteolysis is a major influence on calf lens proteins including the filament networks. Indeed, vimentin and spectrin are substrates for calcium-dependent proteolytic enzymes. ${ }^{57}$ Filensin is also a target of the calciumactivated protease calpain ${ }^{58}$ and it is extensively processed within the lens. ${ }^{45}$ Two major species are generated from filensin that encompass the non- $\alpha$-helical $\mathrm{N}$-terminal head and rod domains (termed the $53 \mathrm{kDa}$ 
fragment $^{9}$ ) and the C-terminal non- $\alpha$-helical domain (apparent mobility equivalent to $\sim 62 \mathrm{kDa}$ by SDS-PAGE ${ }^{58}$ ), indicating that one major site for filensin proteolysis is located close to the junction of the head/rod domain with the tail domain. The processing produces many fragments and there is evidence that it involves more than one pathway. ${ }^{45}$ Comparisons of the C-terminal sequences from rat, mouse, chicken and bovine filensin ${ }^{9}$ reveal a conserved motif very close to this site, and it is tempting to speculate that it is involved in directing the processing events, possibly producing two protein products with different functions.

Removal of the C-terminal tail domain does not affect filament stability since the naturally occurring $53 \mathrm{kDa}$ fragment of filensin is itself sufficient for co-assembly with CP49. ${ }^{9}$ Thus the N-terminal head/rod domain of filensin and CP49 would be expected to remain in a filamentous form during lens fibre cell ageing. There are changes in the subcellular distribution of filensin fragments during fibre cell differentiation. For instance, the C-terminal tail domain of filensin becomes preferentially associated with the plasma membrane of the 'nuclear' fibre cells. ${ }^{45}$ Previous investigations have revealed that the $\mathrm{C}$-terminal tail domain of filensin can interact tightly with the fibre cell plasma membrane, ${ }^{60}$ although the 'receptor' has yet to be identified. When seen in the context of the poor sequence conservation of the C-terminal non- $\alpha$-helical domain of filensin across species, it is difficult to speculate on a specific function for this domain once located to the plasma membrane.

$\mathrm{CP} 49$ is also proteolytically processed during lens fibre differentiation, yielding a major breakdown species of $40 \mathrm{kDa} .{ }^{61} \mathrm{CP} 49$ lacks a C-terminal tail domain and consequently the extent of processing is less when compared with filensin. Analysis of the solubility properties of CP49 during lens fibre cell maturation also reveals a progressive redistribution to the insoluble fraction of the lens. ${ }^{45}$

\section{Phosphorylation of CP49 and filensin in the lens}

Phosphorylation is an important mechanism for controlling the distribution of intermediate filament networks in cells. ${ }^{62}$ It also induces a redistribution of CP49 from the soluble to the insoluble fraction in the chick. ${ }^{63}$ Similarly, analysis of the isoelectric properties of bovine $\mathrm{CP} 49$ reveals that the more basic isoforms are identified within the soluble fraction of the lens whereas more acidic isoforms remain in the insoluble compartment. ${ }^{45}$ The N-terminal head domain of filensin contains a potential phosphorylation site ${ }^{11}$ that is also present in type III intermediate filament proteins.

However, there is currently no evidence to suggest that filensin is extensively phosphorylated in vivo. Proteolysis is therefore a key regulator of filensin function in the lens whereas the contribution of phosphorylation to these functions has yet to be determined.

\section{Intermediate-filament-associated proteins}

The function of intermediate filaments and their association with cell membranes, organelles and other cytoskeletal structures will also be dependent upon intermediate-filament-associated proteins, or IFAPs. These proteins can have devastating effects on intermediate filament function as shown by mutations in the proteins plectin and BPAG-1, which cause skin blistering, muscular dystrophy and neuropathies. ${ }^{21}$ Plectin is also an abundant lens protein ${ }^{64,65}$ and recently it has been proposed to link microtubules to other elements of the cytoskeleton including intermediate filaments. ${ }^{66}$ The distributions of microtubules and intermediate filaments are tightly linked, which might be explained by the action of the IFAP as well as a specific post-translational modification (detyrosination) of tubulin that marks a subset of microtubules for the association. ${ }^{67}$ Another linker protein, IFAP-300, identified within the lens, also associates with vimentin intermediate filaments. ${ }^{68}$ IFAP 300 and plectin are believed to be separate but related proteins ${ }^{69}$ that are both likely to be involved in linking the lens intermediate filaments to either the plasma membrane or to other cytoskeletal elements.

IFAP-300 localises to the fibre cell plasma membrane and during lens fibre cell differentiation its expression is lost. ${ }^{68}$ Plectin expression in the lens has not been so closely examined. Nevertheless, alterations in the distribution of these IFAPs may also contribute to the re-modelling of the vimentin and filensin/CP49 filament networks during lens fibre cell differentiation. It should be noticed that the microtubule distributions within epithelial and fibre cells undergo dramatic redistributions during differentiation. They also disappear from the more differentiated fibre cells. ${ }^{70}$ A direct comparison between changes in the distribution of microtubules, plectin and intermediate filament proteins during fibre cell differentiation has yet to be reported.

In addition to IFAPs the lens epithelial and fibre cells also possess an extensive subplasma membrane network of actin ${ }^{71}$ and its associated cytoskeleton. This includes spectrin, ${ }^{72}$ band $4.1,{ }^{73}$ band $3,^{74}$ ankyrin, ${ }^{74}$ schwannomin ${ }^{75}$ and tropomodulin. ${ }^{76}$ Of these ankyrin is a direct candidate for binding intermediate filaments to the plasma membrane ${ }^{77}$ and once again plectin is a candidate for linking the actin and intermediate filament networks. ${ }^{21}$ The lens apparently lacks localised plasma membrane attachment sites such as desmosomes for intermediate filaments, but plakoglobin ${ }^{78}$ and plakophilin, ${ }^{79}$ which are components of both desmosomes and adherens junctions, are present in the lens. There are cadherin family members present in the lens ${ }^{80,81}$ other than the desmogleins and desmocolins, but how intermediate filaments in the lens are attached to the plasma membrane is still an intriguing question.

The last associated proteins that require mention in the context of intermediate filament function are the $\alpha$-crystallins. These proteins have chaperone activity. ${ }^{82}$ 
Within the lens the $\alpha$-crystallins are intimately associated with the lens cytoskeleton ${ }^{13,19}$ and the 'beads' of beaded filaments have been proposed to be associated $\alpha$-crystallin particles. ${ }^{14}$ The $\alpha$-crystallins are essential to lens function as realised by the discovery of mutations that disrupt their function in the lens. ${ }^{18,26}$ Although both $\alpha \mathrm{A}-, \alpha \mathrm{B}-$ crystallin and the double-knockout mouse have recently been established, ${ }^{83}$ the effect of the removal of $\alpha \mathrm{A}$-crystallin on the lens cytoskeleton, in particular on the vimentin network and the CP49/filensin networks, has yet to be assessed. It is possible that the association of $\alpha$-crystallins regulates intermediate filament sensitivity to proteolysis, or perhaps the association is more to assist the chaperone function of the $\alpha$-crystallins by providing a solid-phase support in the form of the intermediate filaments. These and other questions must be addressed in future investigations.

\section{Conclusion}

Collectively these data confirm CP49 and filensin as two key lens-specific proteins. The future elucidation of the precise role that these proteins play in the lens and identification of those proteins with which they interact in the cytoplasm and at the plasma membrane are therefore of fundamental importance to the understanding of lens fibre cell differentiation and the potential role that $\mathrm{CP} 49$ and filensin play in cataractogenesis. In the context of inherited cataract, details of the chromosomal location for the lens intermediate filament proteins as well as intragenic markers are required. CP49 locates to chromosome $3 q 21-25^{84}$ and filensin is found on chromosome 20p11.23-12.1, ${ }^{7}$ but so far the only intragenic marker identified is for CP49 (Carter et al., manuscript in preparation). Once these molecular tools are available the search for mutations in CP49 and filensin causing lens pathologies can begin.

\section{References}

1. Orii H, Agata K, Sawada K, Eguchi G, Maisel H. Evidence that the chick lens cytoskeletal protein $\mathrm{CP} 49$ belongs to the family of intermediate filament proteins. Curr Eye Res 1993;12:583-8.

2. Hess JF, Casselman JT, FitzGerald PG. cDNA analysis of the $49 \mathrm{kDa}$ lens fibre cell cytoskeletal protein: a new, lens-specific member of the intermediate filament family? Curr Eye Res 1993;12:77-88.

3. Sawada K, Agata J, Eguchi G, Quinlan RA, Maisel H. The predicted structure of $\mathrm{CP} 49$ and a variant thereof, $\mathrm{CP} 49_{\text {ins, }}$, the first vertebrate cytoplasmic intermediate filament protein with a lamin-like insertion in helix 1B. Curr Eye Res 1995;14:545-53.

4. Wallace P, Signer E, Paton IR, Burt D, Quinlan R. The chicken $\mathrm{CP} 49$ gene contains an extra exon compared to the human CP49 gene which identifies an important step in the evolution of the eye lens intermediate filament proteins. Gene 1998;211:19-27.

5. Hess JF, Casselman JT, Fitzgerald PG. Gene structure and cDNA sequence identify the beaded filament protein cp 49 as a highly divergent type-1 intermediate filament protein. J Biol Chem 1996;271:6729-35.
6. Merdes A, Gournari F, Georgatos SD. The 47-kD lens-specific protein phakinin is a tailless intermediate filament protein and an assembly partner of filensin. J Cell Biol 1993;123:1507-16.

7. Rendtorff ND, Hansen C, Silahtaroglu A, Henriksen KF, Tommerup $\mathrm{N}$. Isolation of the human beaded-filament structural protein 1 gene (BFSP1) and assignment to chromosome 20p11.23-p12.1. Genomics 1998;53:114-6.

8. Masaki S, Watanabe T. cDNA sequence analysis of CP94: rat lens fibre cell beaded-filament structural protein shows homology to cytokeratins. Biochem Biophys Res Commun 1992;186:190-8.

9. Masaki S, Quinlan RA. Gene structure and sequence comparisons of the eye lens specific protein, filensin, from rat and mouse: implications for protein classification and assembly. Gene 1997:201:11-20.

10. Remington SG. Chicken filensin: a lens fibre cell protein that exhibits sequence similarity to intermediate filament proteins. J Cell Sci 1993;105:1057-68.

11. Gounari $\mathrm{F}$, et al. Bovine filensin possesses primary and secondary structure similarity to intermediate filament proteins. J Cell Biol 1993;121:847-53.

12. Hess JF, Casselman JT, Kong AP, FitzGerald PG. Primary sequence, secondary structure, gene structure, and assembly properties suggests that the lens-specific cytoskeletal protein filensin represents a novel class of intermediate filament protein. Exp Eye Res 1998;66:625-44.

13. FitzGerald PG, Graham D. Ultrastructural localisation of alpha A-crystallin to the bovine lens fibre cell cytoskeleton. Curr Eye Res 1991;10:417-36.

14. Carter JM, Hutcheson AM, Quinlan RA. In vitro studies on the assembly properties of the lens beaded filament proteins: co-assembly with $\alpha$-crystallin but not with vimentin. Exp Eye Res 1995;60:181-92.

15. Maisel H, Perry MM. Electron microscope observations on some structural proteins of the chick lens. Exp Eye Res 1972;14:7-12.

16. Goulielmos G, et al. Filensin and phakinin form a novel type of beaded intermediate filaments and coassemble de-novo in cultured-cells. J Cell Biol 1996;132:643-55.

17. Goulielmos G, Remington S, Schwesinger F, Georgatos SD, Gounari F. Contributions of the structural domains of filensin in polymer formation and filament distribution. J Cell Sci 1996;109:447-56.

18. Vicart $\mathrm{P}$, et al. A missense mutation in the alpha B-crystallin chaperone gene causes a desmin-related myopathy. Nature Genet 1998;20:92-5.

19. Nicholl ID, Quinlan RA. Chaperone activity of $\alpha$-crystallins modulates intermediate filament assembly. EMBO J 1994;13:945-53.

20. Janmey PA, Euteneuer U, Traub P, Schliwa M. Viscoelastic properties of vimentin compared with other filaments biopolymer networks. J Cell Biol 1991;113:155-60.

21. Fuchs E, Cleveland DW. A structural scaffolding of intermediate filaments in health and disease. Science 1998;279:514-9.

22. McLean WH, et al. Loss of plectin causes epidermolysis bullosa with muscular dystrophy: cDNA cloning and genomic organisation. Genes Dev 1996;10:1724-35.

23. Goldfarb LG, et al. Missense mutations in desmin associated with familial cardiac and skeletal myopathy. Nature Genet 1998;19:402-3.

24. Munoz-Marmol AM, et al. A dysfunctional desmin mutation in a patient with severe generalised myopathy. Proc Natl Acad Sci USA 1998;95:11312-7.

25. Irvine $\mathrm{AD}$, et al. Mutations in cornea-specific keratin $\mathrm{K} 3$ or K12 genes cause Meesmann's corneal dystrophy. Nature Genet 1997;16:184-7.

26. Litt $\mathrm{M}$, et al. Autosomal dominant congenital cataract associated with a missense mutation in the human alpha crystallin gene CRYAA. Hum Mol Genet 1998;7:471-4. 
27. Houseweart MK, Cleveland DW. Intermediate filaments and their associated proteins: multiple dynamic personalities. Curr Opin Cell Biol 1998;10:93-101.

28. Capetanaki Y, Smith S, Heath JP. Overexpression of the vimentin gene in transgenic mice inhibits normal lens cell differentiation. J Cell Biol 1989;109:1653-64.

29. Dunia L, et al. Plasma membrane-cytoskeleton damage in eye lenses of transgenic mice expressing desmin. Eur J Cell Biol 1990;53:59-74.

30. Monteiro MJ, Hoffman PN, Gearhart JD, Cleveland DW. Expression of NF-L in both neuronal and nonneuronal cells of transgenic mice: increased neurofilament density in axons without affecting caliber. J Cell Biol 1990;111:1543-57.

31. Bloemendal H, Raats JM, Pieper FR, Benedetti EL, Dunia I. Transgenic mice carrying chimeric or mutated type III intermediate filament (IF) genes. Cell Mol Life Sci 1997;53:1-12.

32. Becker B, Bellin RM, Sernett SW, Huiatt TW, Robson RM. Synemin contains the rod domain of intermediate filaments. Biochem Biophys Res Commun 1995;213:796-802.

33. Hemken PM, et al. Molecular characteristics of the novel intermediate filament protein paranemin: sequence reveals EAP-300 and IFAPa-400 are highly homologous to paranemin. J Biol Chem 1997;272:32489-99.

34. Quinlan RA, et al. Characterisation of dimer subunits of intermediate filament proteins. J Mol Biol 1986;192:337-49.

35. Söllner P, Quinlan RA, Franke WW. Identification of a distinct soluble subunit of an intermediate filament protein: tetrameric vimentin from living cells. Proc Natl Acad Sci USA 1985;82:7929-33.

36. Quinlan RA, Hutcheson C, Lane B. Intermediate filament proteins. Protein Profiles 1995;2:801-952.

37. Quinlan RA, Carter JM, Sandilands A, Prescott AR. The beaded filament of the eye lens: an unexpected key to intermediate filament structure and function. Trends Cell Biol 1996;6:123-6.

38. Vikstrom KL, Lim SS, Goldman RD, Borisy GG. Steady state dynamics of intermediate filament networks. J Cell Biol 1992;118:121-9.

39. Yoon M, Moir RD, Prahlad V, Goldman RD. Motile properties of vimentin intermediate filament networks in living cells. J Cell Biol 1998;143:147-57.

40. Geisler N, Weber K. Isolation of assembly competent vimentin from porcine eye lens tissue. FEBS Lett 1981;125:253-6.

41. Kasper M, Viebahn C. Cytokeratin expression and early lens development. Anat Embryol Berl 1992;186:285-90.

42. Ellis M, Alousi S, Lawniczak J, Maisel H, Welsh M. Studies on lens vimentin. Exp Eye Res 1984;38:195-202.

43. Sandilands A, et al. Vimentin and CP49/filensin form distinct networks in the lens which are independently modulated during lens fibre cell differentiation. J Cell Sci 1995;108:1397-406.

44. Dahm R, Gribbon C, Quinlan RA, Prescott AR. Changes in the nucleolar and coiled body compartments precede lamina and chromatin reorganisation during fibre cell denucleation in the bovine lens. Eur J Cell Biol 1998;75:237-46.

45. Sandilands A, et al. Filensin is proteolytically processed during lens fibre cell differentiation by multiple independent pathways. Eur J Cell Biol 1995;67:238-53.

46. Bilak SR, et al. Properties of the novel intermediate filament protein synemin and its identification in mammalian muscle. Arch Biochem Biophys 1998;355:63-76.

47. Granger BL, Lazarides E. Synemin: a new high molecular weight protein associated with desmin and vimentin filaments in muscle. Cell 1980;22:727-38.

48. Granger BL, Lazarides E. Expression of the intermediatefilament-associated protein synemin in chicken lens cells. Mol Cell Biol 1984;4:1943-50.
49. Colucci-Guyon E, et al. Mice lacking vimentin develop and reproduce without an obvious phenotype. Cell 1994;79:679-94.

50. Hatfield JS, Skoff RP, Maisel H, Eng L, Bigner DD. The lens epithelium contains glial fibrillary acidic protein (GFAP). J Neuroimmunol 1985;8:347-57.

51. Verderber L, Johnson W, Mucke L, Sarthy V. Differential regulation of a glial fibrillary acidic protein-LacZ transgene in retinal astrocytes and Muller cells. Invest Ophthalmol Vis Sci 1995;36:1137-43.

52. McLean WH, Lane EB. Intermediate filaments in disease. Curr Opin Cell Biol 1995;7:118-125.

53. Steinert PM, Marekov LN, Parry DA. Diversity of intermediate filament structure: evidence that the alignment of coiled-coil molecules in vimentin is different from that in keratin intermediate filaments. J Biol Chem 1993;268:24916-25.

54. Ireland $\mathrm{M}$, Maisel $\mathrm{H}$. A cytoskeletal protein unique to lens fibre cell differentiation. Exp Eye Res 1984;38:637-45.

55. Ireland M, Maisel H. A family of lens fibre cell specific proteins. Lens Eye Toxic Res 1989;6:623-38.

56. FitzGerald PG, Gottlieb W. The $\mathrm{M}_{\mathrm{r}} 115 \mathrm{kD}$ fibre cell-specific protein is a component of the lens cytoskeleton. Curr Eye Res 1989;8:801-11.

57. Truscott RJ, Marcantonio JM, Tomlinson J, Duncan G. Calcium-induced opacification and proteolysis in the intact rat lens. Invest Ophthalmol Vis Sci 1990;31:2405-11.

58. Marcantonio JM. Susceptibility of the bovine lens $115 \mathrm{kDa}$ beaded filament protein to degradation by calcium and calpain. Curr Eye Res 1992;11:103-8.

59. FitzGerald PG. Age-related changes in a fibre cell specific extrinsic membrane protein. Curr Eye Res 1988;7:1255-62.

60. Brunkener M, Georgatos SD. Membrane-binding properties of filensin, a cytoskeletal protein of the lens fibre cells. J Cell Sci 1992;103:709-18.

61. Quinlan RA. The soluble plasma membrane-cytoskeleton complexes and aging in the lens. In: Vrensen GFJM, Clauwaert J, eds. Eye lens membranes and aging, vol 15. Leiden: EURAGE, 1991:171-84.

62. Inagaki $\mathrm{M}$, et al. Dynamic property of intermediate filaments: regulation by phosphorylation. Bioessays 1996;18:481-7.

63. Ireland ME, Klettner C, Nunlee W. Cyclic AMP-mediated phosphorylation and insolubilisation of a 49-kDa cytoskeletal marker protein of lens fibre terminal differentiation. Exp Eye Res 1993;56:453-61.

64. Wiche G, Herrmann H, Leichtfried F, Pytela R. Plectin: a high-molecular-weight cytoskeletal polypeptide component that copurifies with intermediate filaments of the vimentin type. Cold Spring Harbor Symp Quant Biol 1982;46:475-82.

65. Weitzer G, Wiche G. Plectin from bovine lenses: chemical properties, structural analysis and initial identification of interaction partners. Eur J Biochem 1987;169:41-52.

66. Svitkina TM, Verkhovsky AB, Borisy GG. Plectin sidearms mediate interaction of intermediate filaments with microtubules and other components of the cytoskeleton. J Cell Biol 1996;135:991-1007.

67. Gurland G, Gundersen GG. Stable, detyrosinated microtubules function to localise vimentin intermediate filaments in fibroblasts. J Cell Biol 1995;131:1275-90.

68. Lieska N, Shao D, Kriho V, Yang HY. Expression and distribution of cytoskeletal IFAP-300kD as an index of lens cell differentiation. Curr Eye Res 1991;10:1165-74.

69. Skalli O, Jones JC, Gagescu R, Goldman RD. IFAP 300 is common to desmosomes and hemidesmosomes and is a possible linker of intermediate filaments to these junctions. J Cell Biol 1994;125:159-70.

70. Millar A, Hooper A, Copeland L, Cummings F, Prescott A. Reorganisation of the microtubule cytoskeleton and centrosomal loss during lens fibre cell differentiation. Nova Acta Leopoldiana 1997;299:169-83. 
71. Lo WK, Shaw AP, Wen XJ. Actin filament bundles in cortical fibre cells of the rat lens. Exp Eye Res 1997;65:691-701.

72. Aster JC, Brewer GJ, Hanash SM, Maisel H. Band 4.1-like proteins of the bovine lens: effects of differentiation, distribution and extraction characteristics. Biochem J 1984;224:609-16

73. Aster JC, Brewer GJ, Maisel H. The 4.1-like proteins of the bovine lens: spectrin-binding proteins closely related in structure to red blood cell protein 4.1. J Cell Biol 1986;103:115-22.

74. Allen DP, Low PS, Dola A, Maisel H. Band 3 and ankyrin homologues are present in eye lens: evidence for all major erythrocyte membrane components in same non-erythroid cell. Biochem Biophys Res Commun 1987;149:266-75.

75. Claudio JO, Veneziale RW, Menko AS, Rouleau GA. Expression of schwannomin in lens and Schwann cells. Neuroreport 1997;8:2025-30.

76. Woo MK, Fowler VM. Identification and characterisation of tropomodulin and tropomyosin in the adult rat lens. J Cell Sci 1994;107:1359-67.

77. Georgatos SD, Weaver DC, Marchesi VT. Site specificity in vimentin-membrane interactions: intermediate filaments subunits associate with the plasma membrane via their head domains. J Cell Biol 1985;100:1962-7.
78. Franke WW, Kapprell HP, Cowin P. Plakoglobin is a component of the filamentous subplasmalemmal coat of lens cells. Eur J Cell Biol 1987;43:301-15.

79. Heid HW, et al. Cell type-specific desmosomal plaque proteins of the plakoglobin family: plakophilin 1 (band 6 protein). Differentiation 1994;58:113-31.

80. Watanabe M, Kobayashi H, Yao R, Maisel H. Adhesion and junction molecules in embryonic and adult lens cell differentiation. Acta Ophthalmol Suppl 1992;205:46-52.

81. Graham C, Wistow G. The predominant cadherin in fetal human lens is identical to N-cadherin and is not a candidate locus for the Marner cataract [letter]. Exp Eye Res 1994;59:373-6.

82. Horwitz J. Alpha-crystallin can function as a molecular chaperone. Proc Natl Acad Sci USA 1992;89:10449-53.

83. Brady JP, et al. Targeted disruption of the mouse alpha A-crystallin gene induces cataract and cytoplasmic inclusion bodies containing the small heat shock protein alpha B-crystallin. Proc Natl Acad Sci USA 1997;94:884-9.

84. Hess JF, Casselman JT, Fitzgerald PG. Chromosomal locations of the genes for the beaded filament proteins cp- 115 and cp-47. Curr Eye Res 1995;14:11-8. 